\title{
Survival after Combined Hepatic Metastasectomy and Chemotherapy in Patients with Concurrent Hepatic and Extrahepatic Colorectal Metastases: a SEER Database Analysis
}

Inas Uthman

Suez Canal University Faculty of Medicine

Ahmed M Fouad

Suez Canal University Faculty of Medicine

Islam Khaled

Suez Canal University Faculty of Medicine

Mohammed Faisal ( $\sim$ m.faisal@med.suez.edu.eg)

Suez Canal University Faculty of Medicine https://orcid.org/0000-0002-2162-1741

Research

Keywords: Colorectal cancer, colorectal liver metastasis, hepatic metastasectomy, extrahepatic disease and SEER

Posted Date: September 15th, 2020

DOI: https://doi.org/10.21203/rs.3.rs-74826/v1

License: (c) (i) This work is licensed under a Creative Commons Attribution 4.0 International License.

Read Full License 


\section{Abstract}

\section{Purpose}

Colorectal cancer is the second leading cause of death among all cancers worldwide. Hepatic metastases exist in approximately $50 \%$ of colorectal cancer patients. The purpose of this study was to assess the effect of combined hepatic metastasectomy and chemotherapy on overall survival in patients with concurrent hepatic and extrahepatic disease.

\section{Methods}

A total of 2533 patients from the US Surveillance, Epidemiology, and End Results (SEER) database with concurrent colorectal liver metastasis (CRLM) and extrahepatic disease (EHD) between January 1, 2010, and December 31, 2014, were retrieved. Survival analysis with Kaplan-Meier and Cox regression analyses was performed to assess the effect of combined hepatic metastasectomy and chemotherapy on 5-year survival.

Results

Two hundred and fourteen (8.4\%) patients underwent combined hepatic metastasectomy and chemotherapy. The median survival time among patients who underwent combined hepatic metastasectomy and chemotherapy was significantly higher than that of patients who underwent chemotherapy alone (24 vs. 21 months; $p<0.0001$ ). Furthermore, older age at diagnosis ( $\geq 60$ years), American Indian/Alaska Native race, primary sites at the rectosigoid colon, sigmoid colon, and descending colon, grade III, and the presence of bone metastases were all significantly associated with higher 5-year mortality. Patients who underwent combined hepatic metastasectomy and chemotherapy were significantly associated with $22.2 \%$ less 5 -year mortality than patients who received chemotherapy alone.

Conclusion

Combined hepatic metastasectomy with chemotherapy in CRLM patients with EHD yields better survival than chemotherapy alone.

\section{Background}

Worldwide, colorectal cancers are the third most common cancer and the fourth most common cause of cancer-related deaths [1]. The most common site of metastasis in colorectal cancer is in the liver, owing to its portal circulation [2]. Approximately one-fourth of colorectal cancer patients present with liver metastasis at the time of diagnosis, and another $40-50 \%$ will develop liver metastasis later [3-6]. In the absence of proper treatment, patients with colorectal liver metastatic disease (CRLM) have a very poor survival, with a reported median survival lying between 6-9 months, and even with the best regimens of chemotherapy, the median survival of unresectable disease does not usually exceed 18 months [7]. 
However, with the advances that medicine has witnessed over the past few decades, the median survival of CRLM patients has successfully jumped to forty months with the implementation of liver resection [7].

Meanwhile, the presence of a concurrent extrahepatic disease (EHD) in patients with CLRM has long been viewed as an absolute contraindication for liver resection. Nevertheless, more patients with EHD are becoming eligible for liver resection with the development of better surgical techniques [8,9]. Certain clinicopathological features have been identified that suggest which patients could benefit from liver resection. For instance, a study [10] proposed five factors that indicate a poor prognosis, including rightsided colon cancer, at least six liver metastases, EHD location other than lung metastases, EHD concomitant with CLM recurrence, and a carcinoembryonic antigen (CEA) level $\geq 10 \mathrm{ng} / \mathrm{mL}$. They found that patients had a higher 5-year survival rate in the absence of those factors. Therefore, this study aimed to retrospectively assess the consequences of liver resection added to chemotherapy on the overall survival of patients with CRLM and concurrent EHD and to identify the characteristics of the patients who would benefit from such a combination.

\section{Patients And Methods}

\subsection{Data Source}

This retrospective cohort study made use of the Surveillance, Epidemiology, and End Results (SEER) database. After obtaining the SEER permission to use patient data, we surveyed the SEER ${ }^{\star S t a t}$ database (version 8.3.6; National Cancer Institute) and collected the data of 2533 CRLM patients with concurrent EHD.

\subsection{Patient Population}

We selected the patients based on the following selection criteria:

- Cases diagnosed between January 1,2010, and December 31, 2014. Data on the specific site of distant metastasis have only become available on the SEER database since 2010, and therefore, patients diagnosed before 2010 were excluded. We also excluded patients diagnosed after 2015 to allow for a follow-up interval of at least 60 months.

- Patients with adenocarcinoma (ICD-0-3 hist/behav:8140/3: Adenocarcinoma, not otherwise specified [NOS]), stage M1b (AJCC M, 7th edition staging system), located at the ascending colon (code C18.2), hepatic flexure (code C18.3), transverse colon (code C18.4), splenic flexure (code C18.5), descending colon (code C18.6), sigmoid colon (code C18.7), recto-sigmoid junction (code C19.9), and rectum, NOS (code C20.9). We excluded tumors located in the cecum (code c18.0), appendix (code C18.1), overlapping lesions of the colon (code C18.8), and colon NOS (code C18.9).

- Patients with liver metastasis (CS mets at DX-liver), along with an extrahepatic disease, including lung (CS mets at DX-lung), brain (CS mets at DX-brain), bone (CS mets at DX-bone), and peritoneal carcinomatosis (CS Mets at DX: code 36). 
- All selected patients received systemic chemotherapy, either alone or combined with hepatic resection/ablation (nonprimary surgical procedure to distant site). Those who received radiation were excluded.

- Patients alive with no survival time were excluded; these included 80 patients. None of our patients were diagnosed by autopsy or reported on a death certificate.

The length of survival was measured from the date of diagnosis until the time of death or the last followup. According to SEER data, all these patients had been adequately followed-up at the time of study cutoff (December 31, 2014). However, the actual follow-up protocol was not stated.

\subsection{Statistical Analysis:}

All statistical analyses were performed with IBM SPSS statistical software (version 25). Frequency distributions (No. and \%) were used to describe categorical variables (e.g., age at diagnosis, sex, race, primary site, grade, and sites of extra-hepatic metastases, hepatic metastasectomy). Mean and the standard deviation was used to describe age at diagnosis as a continuous variable. Association between categorical variables and hepatic metastasectomy were tested for statistical analysis by Chi-square test or Fisher's exact test (if $>20 \%$ of expected values were less than 5 ). Difference in the mean age (a continuous variable) by the hepatic metastasectomy status (Yes/No) was tested for statistical significance by the independent-samples T-test. Overall survival time (in months) was described as the median survival. Survival function was presented in the Kaplan-Meier curve, while the difference in the survival distributions for "hepatic metastasectomy" and "no surgery" subgroups was tested for the statistical significance by the Log-rank test. Survival data were further modeled using Cox proportionalhazards regression. The Cox models were used to assess the association of the study covariates (age at diagnosis, sex, race, primary site, grade, and sites of extra-hepatic metastases) and surgical intervention (hepatic metastasectomy) with the 5-year mortality. The hepatic metastasectomy model (model 1) was then adjusted for sex, age at diagnosis ( $<60$ years, or $\geq 60$ years), and race (model 2); and for the primary site, grade, and sites of extra-hepatic metastases (model 3). Cox proportional hazard ratios and its $95 \%$ confidence intervals were presented for each covariate and each hepatic metastasectomy model. A pvalue $<0.05$ was regarded as statistically significant.

\section{Results}

Out of 2533 patients who had a diagnosis of CRLM and concurrent EHD, $57.2 \%$ were male and $42.8 \%$ were female (Table 1$)$. The mean age of the studied sample was 60.13 years $( \pm 12.51)$ and ranged from 16 to 95 years. Fifty-three percent were aged 60 years old or older. The majority were white $(73.5 \%)$. Approximately half of the patients presented with grade II colorectal cancer (53.8\%), while $15.3 \%$ were at grade III, and $25 \%$ were of unknown grade. Among the different sites of primary colorectal tumors, the sigmoid colon was the most common (31.1\%), closely followed by the rectum NOS (21.4), while splenic flexure was the least common (2.9\%). Approximately two-thirds of the patients had lung metastases at 
the time of presentation ( $67.9 \%)$, followed by metastases in the peritoneum $(26.8 \%)$, bones $(5.0 \%)$ and the brain $(0.4 \%)$. 
Table 1

Demographic and pathological characteristics of studied sample $(\mathrm{N}=2533)$

\begin{tabular}{|c|c|c|c|}
\hline & & No. & Column \% \\
\hline \multirow[t]{2}{*}{ Age at diagnosis } & $<60$ & 1190 & $47.0 \%$ \\
\hline & $>=60$ & 1343 & $53.0 \%$ \\
\hline \multirow[t]{2}{*}{ Sex } & Male & 1448 & $57.2 \%$ \\
\hline & Female & 1085 & $42.8 \%$ \\
\hline \multirow[t]{5}{*}{ Race } & White & 1861 & $73.5 \%$ \\
\hline & Black & 385 & $15.2 \%$ \\
\hline & Asisn or Pacific Islander & 255 & $10.1 \%$ \\
\hline & American Indian/Alaska Native & 28 & $1.1 \%$ \\
\hline & Unknown & 4 & $0.2 \%$ \\
\hline \multirow[t]{8}{*}{ Primary Site } & Ascending colon & 383 & $15.1 \%$ \\
\hline & Hepatic flexure of colon & 104 & $4.1 \%$ \\
\hline & Transverse colon & 162 & $6.4 \%$ \\
\hline & Splenic flexure of colon & 74 & $2.9 \%$ \\
\hline & Descending colon & 156 & $6.2 \%$ \\
\hline & Sigmoid colon & 788 & $31.1 \%$ \\
\hline & Rectosigmoid colon & 325 & $12.8 \%$ \\
\hline & Rectum, NOS & 541 & $21.4 \%$ \\
\hline \multirow[t]{5}{*}{ Grade } & Well differentiated; Grade I & 93 & $3.7 \%$ \\
\hline & Moderately differentiated; Grade II & 1362 & $53.8 \%$ \\
\hline & Poorly differentiated; Grade III & 387 & $15.3 \%$ \\
\hline & Undifferentiated (anaplastic); Grade IV & 58 & $2.3 \%$ \\
\hline & Unknown & 633 & $25.0 \%$ \\
\hline \multirow[t]{3}{*}{ Site of Extrahepatic Mets } & Lung & 1719 & $67.9 \%$ \\
\hline & Peritoneum & 678 & $26.8 \%$ \\
\hline & Bone & 127 & $5.0 \%$ \\
\hline NOS: Not Otherwise Speci & & & \\
\hline
\end{tabular}




\begin{tabular}{|llll|}
\hline & & No. & Column \% \\
\hline & Brain & 9 & $0.4 \%$ \\
\hline Surgical Resection & No surgery & 2319 & $91.6 \%$ \\
\cline { 2 - 4 } & Hepatic Metastectomy & 214 & $8.4 \%$ \\
\hline NOS: Not Otherwise Specified & & \\
\hline
\end{tabular}

Two hundred and fourteen patients (8.4\%) with CRLM and concurrent EHD underwent surgical removal or ablation of their liver metastasis combined with systemic chemotherapy, while 2319 (91.6\%) patients received systemic chemotherapy only (Table 1 ). The maximum follow-up time of patients in this study was five years. The median overall survival time was 21.0 months ( $95 \% \mathrm{Cl}: 20.39-21.61)$. Patients who underwent "hepatic metastasectomy" survived significantly longer than patients who did not; 24.0 months ( $95 \% \mathrm{Cl}: 0.86-22.32)$ compared to 21.0 months ( $95 \% \mathrm{Cl}: 0.34-20.34)$, respectively. The survival distributions for both groups were significantly different, $\chi 2(1)=18.58, p<0.0001$ (Fig. 1). In Table 2, CRLM patients who underwent hepatic metastasectomy were significantly associated with younger age at diagnosis (<60 years), female sex, primary site, tumor grade, and site of extrahepatic metastases. 
Table 2

Distribution of demographic and tumor characteristics of metastatic colorectal cancer patients by surgical intervention (Hepatic Metastasectomy) $(\mathrm{N}=2533)$.

\begin{tabular}{|c|c|c|c|c|c|c|}
\hline \multicolumn{2}{|c|}{ Patients' Characteristics } & \multicolumn{4}{|c|}{ Hepatic Metastasectomy } & \multirow{4}{*}{$\begin{array}{l}p- \\
\text { value } \\
< \\
0.001 *\end{array}$} \\
\hline & & \multicolumn{2}{|l|}{ No } & \multicolumn{2}{|l|}{ Yes } & \\
\hline \multirow{3}{*}{$\begin{array}{l}\text { Age at diagnosis } \\
\text { (years) }\end{array}$} & $<60$ & 1058 & $45.6 \%$ & 132 & $61.7 \%$ & \\
\hline & $\geq 60$ & 1261 & $54.4 \%$ & 82 & $38.3 \%$ & \\
\hline & Mean \pm SD & \multicolumn{2}{|c|}{$60.5 \pm 12.5$} & \multicolumn{2}{|c|}{$56.5 \pm 12.2$} & ¿.001* \\
\hline \multirow[t]{2}{*}{ Sex } & Male & 1347 & $58.1 \%$ & 101 & $47.2 \%$ & \multirow[t]{2}{*}{$0.002^{*}$} \\
\hline & Female & 972 & $41.9 \%$ & 113 & $52.8 \%$ & \\
\hline \multirow[t]{5}{*}{ Race } & White & 1695 & $73.1 \%$ & 166 & $77.6 \%$ & \multirow[t]{5}{*}{0.288} \\
\hline & Black & 355 & $15.3 \%$ & 30 & $14.0 \%$ & \\
\hline & Asian or Pacific Islander & 239 & $10.3 \%$ & 16 & $7.5 \%$ & \\
\hline & $\begin{array}{l}\text { American Indian/Alaska } \\
\text { Native }\end{array}$ & 27 & $1.2 \%$ & 1 & $0.5 \%$ & \\
\hline & Unknown & 3 & $0.1 \%$ & 1 & $0.5 \%$ & \\
\hline \multirow[t]{8}{*}{ Primary Site } & Ascending colon & 357 & $15.4 \%$ & 26 & $12.1 \%$ & \multirow{8}{*}{ <.001* } \\
\hline & Hepatic flexure of colon & 96 & $4.1 \%$ & 8 & $3.7 \%$ & \\
\hline & Transverse colon & 143 & $6.2 \%$ & 19 & $8.9 \%$ & \\
\hline & Splenic flexure of colon & 64 & $2.8 \%$ & 10 & $4.7 \%$ & \\
\hline & Descending colon & 132 & $5.7 \%$ & 24 & $11.2 \%$ & \\
\hline & Sigmoid colon & 707 & $30.5 \%$ & 81 & $37.9 \%$ & \\
\hline & Recto-sigmoid colon & 303 & $13.1 \%$ & 22 & $10.3 \%$ & \\
\hline & Rectum, NOS & 517 & $22.3 \%$ & 24 & $11.2 \%$ & \\
\hline \multirow[t]{5}{*}{ Grade } & Grade I & 85 & $3.7 \%$ & 8 & $3.7 \%$ & \multirow{5}{*}{ <. $001 *$} \\
\hline & Grade II & 1232 & $53.1 \%$ & 130 & $60.7 \%$ & \\
\hline & Grade III & 347 & $15.0 \%$ & 40 & $18.7 \%$ & \\
\hline & Grade IV & 48 & $2.1 \%$ & 10 & $4.7 \%$ & \\
\hline & Unknown & 607 & $26.2 \%$ & 26 & $12.1 \%$ & \\
\hline
\end{tabular}

*. Statistically significant $p$-value $(p<0.05)$ 


\begin{tabular}{|lllllll|}
\hline $\begin{array}{l}\text { Site of Extrahepatic } \\
\text { Mets }\end{array}$ & Lung & 1623 & $70.0 \%$ & 96 & $44.9 \%$ & \multirow{0}{*}{ 0.001* } \\
\cline { 2 - 6 } & Peritoneum & 566 & $24.4 \%$ & 112 & $52.3 \%$ & \\
\cline { 2 - 6 } & Bone & 122 & $5.3 \%$ & 5 & $2.3 \%$ \\
\cline { 2 - 6 } & Brain & 8 & $0.3 \%$ & 1 & $0.5 \%$ \\
\hline *. Statistically significant & p-value $(p<0.05)$ & & & & \\
\hline
\end{tabular}

Table 3 shows that older age at diagnosis ( $\geq 60$ years) and American Indian/Alaska Native race were significantly associated with a higher 5-year mortality hazard compared to earlier age at diagnosis (< 60 years) and white race, respectively. No statistically significant sex difference was detected in the 5year mortality hazard ratio. Furthermore, primary sites at the rectosigmoid colon, sigmoid colon, and descending colon, grade III, and the presence of bone metastases were all significantly associated with a higher 5-year mortality hazard compared to rectum (or NOS), grade I, and lung metastases. However, surgical intervention by hepatic metastasectomy was associated with a $33.8 \%$ lower 5 -year mortality hazard compared to no surgical interventions (i.e., chemotherapy only). 
Table 3

Unadjusted Cox proportional hazard ratio (HR) for the 5-year mortality according to patients' characteristics.

\begin{tabular}{|c|c|c|c|c|}
\hline & & No. of & Unadjusted & 95\% Confidence \\
\hline & & (row \%) & HR & \\
\hline Age at diagnosis & $<60$ years & $\begin{array}{l}317 \\
(26.6 \%)\end{array}$ & 1 & - \\
\hline & $\geq 60$ years & $\begin{array}{l}581 \\
(43.3 \%)\end{array}$ & $1.850 *$ & $1.613-2.122$ \\
\hline Sex & Female & $\begin{array}{l}379 \\
(34.9 \%)\end{array}$ & 1 & - \\
\hline & Male & $\begin{array}{l}519 \\
(35.8 \%)\end{array}$ & 1.025 & $0.898-1.170$ \\
\hline Race & White & $\begin{array}{l}641 \\
(34.4 \%)\end{array}$ & 1 & - \\
\hline & Black & $\begin{array}{l}150 \\
(39.0 \%)\end{array}$ & 1.156 & $0.967-1.381$ \\
\hline & Asian or Pacific Islander & 89 (34.9\%) & 1.012 & $0.811-1.263$ \\
\hline & $\begin{array}{l}\text { American Indian/Alaska } \\
\text { Native }\end{array}$ & $16(57.1 \%)$ & $1.917 *$ & $1.167-3.149$ \\
\hline & Unknown & $2(50.0 \%)$ & 1.841 & $0.459-7.379$ \\
\hline Primary Site & Rectum, NOS & $\begin{array}{l}159 \\
(29.4 \%)\end{array}$ & 1 & - \\
\hline & Recto-sigmoid colon & $\begin{array}{l}111 \\
(34.2 \%)\end{array}$ & $1.813^{*}$ & $1.464-2.246$ \\
\hline & Sigmoid colon & $\begin{array}{l}263 \\
(33.4 \%)\end{array}$ & $1.761^{*}$ & $1.275-2.433$ \\
\hline & Descending colon & $53(34.0 \%)$ & $1.484^{\star}$ & $1.112-1.980$ \\
\hline & Splenic flexure of colon & $21(28.4 \%)$ & 0.987 & $0.626-1.555$ \\
\hline & Transverse colon & $65(40.1 \%)$ & 0.211 & $0.894-1.664$ \\
\hline & Hepatic flexure of colon & $48(46.2 \%)$ & 0.139 & $0.953-1.413$ \\
\hline & Ascending colon & $\begin{array}{l}178 \\
(46.5 \%)\end{array}$ & 0.111 & $0.956-1.552$ \\
\hline
\end{tabular}

HR, Cox Proportional Hazard Ratio; Cl, Confidence Interval.

*. Statistically significant $p$-value $(<0.05)$. 


\begin{tabular}{|c|c|c|c|c|}
\hline & & $\begin{array}{l}\text { No. of } \\
\text { Deaths } \\
\text { (row \%) }\end{array}$ & $\begin{array}{l}\text { Unadjusted } \\
\text { HR }\end{array}$ & $\begin{array}{l}\text { 95\% Confidence } \\
\text { Interval }\end{array}$ \\
\hline \multirow[t]{5}{*}{ Grade } & Grade I & $26(28.0 \%)$ & 1 & - \\
\hline & Grade II & $\begin{array}{l}412 \\
(30.2 \%)\end{array}$ & 1.096 & $0.738-1.630$ \\
\hline & Grade III & $\begin{array}{l}165 \\
(42.6 \%)\end{array}$ & $1.694^{*}$ & $1.120-2.562$ \\
\hline & Grade IV & $25(43.1 \%)$ & 1.669 & $0.964-2.891$ \\
\hline & Unknown & $\begin{array}{l}270 \\
(42.7 \%)\end{array}$ & $1.724^{\star}$ & $1.152-2.578$ \\
\hline \multirow[t]{4}{*}{$\begin{array}{l}\text { Site of Extrahepatic } \\
\text { Mets }\end{array}$} & Lung & $\begin{array}{l}611 \\
(35.5 \%)\end{array}$ & 1 & - \\
\hline & Peritoneum & $\begin{array}{l}225 \\
(33.2 \%)\end{array}$ & 0.912 & $0.783-1.063$ \\
\hline & Bone & $59(46.5 \%)$ & $1.420^{\star}$ & $1.087-1.855$ \\
\hline & Brain & $3(33.3 \%)$ & 1.004 & $0.323-3.121$ \\
\hline \multirow[t]{2}{*}{ Surgical } & No Surgery & $\begin{array}{l}842 \\
(36.3 \%)\end{array}$ & REF & \\
\hline & Hepatic Metastasectomy & $56(26.2 \%)$ & $0.662^{\star}$ & $0.505-0.867$ \\
\hline \multicolumn{5}{|c|}{ HR, Cox Proportional Hazard Ratio; Cl, Confidence Interval. } \\
\hline \multicolumn{5}{|c|}{ *. Statistically significant p-value $(<0.05)$} \\
\hline
\end{tabular}

Cox regression (Table 4) revealed that CRLM patients who underwent hepatic metastasectomy had a significantly lower 5-year mortality hazard (33.8\%) than patients who did not (model 1). When adjusting for age at diagnosis, sex, and race of patients (model 2), hepatic metastasectomy was associated with a significantly $27.1 \%$ lower 5-year mortality hazard compared to patients with no surgical intervention. Further adjustment for clinicopathological characteristics (model 3) revealed a 22.2\% lower 5-year mortality hazard among patients who underwent hepatic metastasectomy compared to patients who did not. Change in model fit (-two Log Likelihood), following each adjustment step, was statistically significant ( $p$-value $<0.05)$. 
Table 4

Comparison of the predictive capability of hepatic metastasectomy models for the 5-year mortality hazard.

\begin{tabular}{|llll|}
\hline & $\begin{array}{l}\text { Model 1 } \\
\text { HR (95\% Cl) }\end{array}$ & $\begin{array}{l}\text { Model 2 } \\
\text { HR (95\% Cl) }\end{array}$ & $\begin{array}{l}\text { Model 3 } \\
\text { HR (95\% Cl) }\end{array}$ \\
\hline Hepatic Metastectomy & $0.662(0.505-0.867)$ & $0.729(0.555-0.956)$ & $0.778(0.590-1.026)$ \\
\hline Harrel's C & 0.516 & 0.593 & 0.630 \\
\hline-2 Log Likelihood & 13735.151 & 13647.798 & 13567.975 \\
\hline Chi-square (df) & $10.120(1)$ & $87.353(6)$ & $79.823(14)$ \\
\hline p-value & $0.001 *$ & $<0.001^{*}$ & $<0.001^{*}$ \\
\hline & $33.8 \%$ & $27.1 \%$ & $22.2 \%$ \\
\hline $\begin{array}{l}\text { Model 1: Crude model (unadjusted). Model 2: adjusted for age at diagnosis, sex, and race. Model 3: } \\
\text { adjusted for age at diagnosis, sex, race, primary site, grade, and site of extrahepatic metastases. }\end{array}$ \\
\hline HR, Cox Proportional Hazard Ratio; Cl, Confidence Interval. & \\
\hline *. Statistically significant p-value $(<0.05)$. & & \\
\hline
\end{tabular}

\section{Discussion}

The presence of extrahepatic disease (EHD) in patients with CLRM was previously regarded as an absolute contraindication for liver resection $[11,12]$. However, with the development of better surgical techniques that allow for complete resection and the emergence of more effective regimens of chemotherapy that shrink both intra- and extrahepatic disease, more patients with EHD are becoming eligible for liver resection $[11,12]$. It depends on the possibility of resecting all diseases, including the primary tumor, liver metastases, and EHD $[13,14]$. This study revealed that, in CRLM patients with concurrent EHD, resection of liver metastases following systemic chemotherapy is superior to chemotherapy alone, with median OS times of 24 months and 21 months, respectively. Chua et al. clarified that surgery removes the tumor mass, while chemotherapy targets micrometastatic disease [15]. Therefore, combining both modalities would lead to better outcomes. We found that the survival of CRLM patients with EHD who received combined regimens was not influenced by their sex; however, patients with a younger age at diagnosis and white race had a lower 5-year mortality hazard. Meanwhile, a study by Aoki et al. indicated that patient age and sex were insignificant prognostic factors [16]. Surprisingly, Adam et al. reported impressive survival rates of elderly CRLM patients undergoing liver resection and concluded that patients' age should not be regarded as a barrier to surgery [17].

Our study showed that patients had outcomes that were more favorable when their primary tumors were grade I, located at the rectum, or when they had an EHD located at the lungs. Similarly, a study observed more reduced survival rates following liver resection in patients with liver metastases from right-sided 
colon cancer [18]. In contrast, Aoki et al. found no significant differences in overall survival between different sites of the primary tumor [16]. Meanwhile, it has been consistently reported in the literature that the location of EHD is an essential prognostic factor $[10,19,20]$. A study found that following complete resection of the EHD, patients with lung metastasis had a better prognosis compared to those with peritoneal or portal and para-aortic nodal metastases[21]. Interestingly, a study by Adam et al. proposed five factors for poor prognosis: right colon cancer, at least 6 liver metastases, EHD location other than lung metastases, EHD concomitant with CLM recurrence, and a carcinoembryonic antigen (CEA) level $\geq$ $10 \mathrm{ng} / \mathrm{mL}[10]$. The authors observed a higher 5-year survival rate in patients with none of these factors compared to that of patients with three or more factors. Other studies have also addressed further negative prognostic factors, including R1 margin status, largest CRLM greater than $3 \mathrm{~cm}$, portal or retroperitoneal nodal involvement, multiple EHD sites, and high tumor burden in the liver[19, 22-24]. Furthermore, Chua et al identified the Peritoneal Cancer Index (PCl) as a prognostic indicator of survival in CRLM patients with peritoneal carcinomatosis[25]. Lower $\mathrm{PCl}$ in these patients made it possible to perform complete cytoreductive surgery for peritoneal disease and thus improved their survival.

To date, the possibility of liver resection to offer a potential cure for patients with EHD is still a debate. Some studies found that disease recurrence is the rule in these patients $[19,26]$. For instance, a retrospective review reported a very high rate of disease recurrence following resection, with $90.2 \%$ of patients experiencing recurrence at a median of 8 months and $85 \%$ of them experiencing systemic recurrence [19]. The patients were rarely cured, and therefore, they considered liver resection in this setting as a non-curative intervention $[19,27]$. In contrast, some have postulated that combining targeted molecular therapies with chemotherapy or following a more aggressive approach may offer a potential cure in CRLM patients with concomitant EHD $[11,28]$. Such an approach consists of perioperative chemotherapy, resection of all metastatic sites, and re-surgery in case of recurrence $[11,28]$. However, even in the absence of curative intent, complete resection is needed to achieve better outcomes. Patients who did not complete two-stage hepatectomy had similar survival rates to patients treated with chemotherapy only [29]. Moreover, the survival of patients undergoing combined resection of CRLM and EHD was better than that of patients undergoing liver resection only or those receiving chemotherapy only $[23,30]$. For instance, Hwang et al. indicated that the 5 -year overall survival of patients significantly jumped from $0-28 \%$ after resecting both hepatic and concurrent EHD [23].

The current study had several limitations. The data on SEER*Stat only report whether the patient has received chemotherapy or not. Further details of the chemotherapy regimen are not available in SEER, including the given agents and their combinations, the number of cycles, and the sequence of chemotherapy with surgery, preoperative, postoperative, or both. Another limitation is the lack of details about hepatic metastases, including their size and number. Such a shortage in detail has limited our ability to analyze the effect of various chemotherapy protocols and liver disease burden on patient outcomes following liver resection. Moreover, SEER ${ }^{*}$ Stat describes liver resection with resection/ablation without further details on the resection technique. 


\section{Conclusion}

This study revealed that CRLM patients with EHD could benefit from combined liver metastases and chemotherapy in terms of better survival. Future studies should address the most appropriate chemotherapy regimen in this setting and assess the effect of combined CRLM and EHD resection at different sites on patient survival.

\section{Abbreviations}

\begin{tabular}{|ll|}
\hline CRLM & Colorectal Liver Metastasis \\
\hline EHD & Extrahepatic Disease \\
\hline SEER & Surveillance, Epidemiology, and End Results Program \\
\hline AJCC & American Joint Committee on Cancer \\
\hline Hist/Behav & Histology/Behavior \\
\hline NOS & Not Otherwise Specified \\
\hline CS & Collaborative Stage \\
\hline Mets & Metastases \\
\hline DX & Diagnosis \\
\hline PCI & Peritoneal Cancer Index \\
OS & Overall survival \\
\hline
\end{tabular}

\section{Declarations}

\subsection{Ethics approval and consent to participate}

Cancer patient data were collected from the SEER database after approval. A data use agreement form was signed, and the authors had to use a username and password to log in and collect the data.

\subsection{Consent for publication}

Not applicable.

\subsection{Availability of data and material}

The findings of this study were based upon data obtained from the SEER database; restrictions apply to the availability of these data, which were used under license for the current study and so are not available 
for public use. However, the data are available upon requests directed to the authors and with permission from SEER.

\subsection{Conflicts of interest}

The authors declare no conflicts of interest.

\subsection{Funding}

The authors declare that no funding was received.

\subsection{Authors' contributions}

The study concept was evaluated by IU, and MF extracted the data of cancer patients from the SEER database. These two authors also analyzed the data. IK and IA wrote the background section of this manuscript, IU and AF wrote the methods and results sections, and IU and MF wrote the discussion section. Referencing was performed by MF. IU, MF, AF reviewed and proofread the article. All authors read and approved the final manuscript.

\subsection{Acknowledgments}

The authors wish to thank Dr Doaa Omar M. BBCh and Ahmed Meshref MBBCh for their helpful support and guidance during data extraction from SEER.

\section{References}

1. Kuipers EJ, Grady WM, Lieberman D, Seufferlein T, Sung JJ, Boelens PG, et al. Colorectal cancer. Nat Rev Dis Primers. 2015;1:15065.

2. Sheth KR, Clary BM. Management of hepatic metastases from colorectal cancer. Clin Colon Rectal Surg United States. 2005;18:215-23.

3. Shah SA, Bromberg R, Coates A, Rempel E, Simunovic M, Gallinger S. Survival after liver resection for metastatic colorectal carcinoma in a large population. J Am Coll Surgeons United States. 2007;205:676-83.

4. Wang K, Liu W, Yan X-L, Xing B-C. Role of a liver-first approach for synchronous colorectal liver metastases. World J Gastroenterol United States. 2016;22:2126-32.

5. Andersen PS, Hornbech K, Larsen PN, Ravn J, Wettergren A. Surgical treatment of synchronous and metachronous hepatic-and pulmonary colorectal cancer metastases-the Copenhagen experience. Eur Surg Springer. 2012;44:400-7. 
6. Chua TC, Saxena A, Chu F, Zhao J, Morris DL. Predictors of cure after hepatic resection of colorectal liver metastases: an analysis of actual 5- and 10-year survivors. J Surg Oncol United States. 2011;103:796-800.

7. Stewart CL, Warner S, Ito K, Raoof M, Wu GX, Kessler J, et al. Cytoreduction for colorectal metastases: liver, lung, peritoneum, lymph nodes, bone, brain. When does it palliate, prolong survival, and potentially cure? Curr Probl Surg. 2018/10/04. 2018;55:330-79.

8. Byam J, Reuter NP, Woodall CE, Scoggins CR, Mcmasters KM, Martin RCG. Should Hepatic Metastatic Colorectal Cancer Patients with Extrahepatic Disease Undergo Liver Resection / Ablation? Ann Surg Oncol. 2009;3064-9.

9. Adam R, de Haas RJ, Wicherts DA, Aloia TA, Delvart V, Azoulay D, et al. Is hepatic resection justified after chemotherapy in patients with colorectal liver metastases and lymph node involvement? J Clin Oncol. 2008;26:3672-80.

10. Adam R, Haas RJ, De, Wicherts DA, Vibert E, Salloum C, Azoulay D, et al. Concomitant Extra-hepatic Disease in Patients With Colorectal liver metastases: when is there a place of surgery? Ann Surg. 2011;253:349-59.

11. Adam R, de Haas RJ, Wicherts DA, Aloia TA, Delvart V, Azoulay D, et al. Is Hepatic Resection Justified After Chemotherapy in Patients With Colorectal Liver Metastases and Lymph Node Involvement? J Clin Oncol. 2008;26:3672-80.

12. Byam J, Reuter NP, Woodall CE, Scoggins CR, McMasters KM, Martin RCG. Should Hepatic Metastatic Colorectal Cancer Patients with Extrahepatic Disease Undergo Liver Resection/Ablation? Ann Surg Oncol. 2009;16:3064-9.

13. Chow FC-L, Chok KS-H. Colorectal liver metastases: An update on multidisciplinary approach. World J Hepatol. 2019;11:150-72.

14. Van Cutsem E, Cervantes A, Adam R, Sobrero A, Van Krieken JH, Aderka D, et al. ESMO consensus guidelines for the management of patients with metastatic colorectal cancer. Ann Oncol. 2016;27:1386-422.

15. Chua TC, Saxena A, Liauw W, Chu F, Morris DL. Hepatectomy and resection of concomitant extrahepatic disease for colorectal liver metastases-a systematic review. Eur J Cancer. 2012;48:1757-65.

16. Aoki T, Umekita N, Tanaka S, Noda K, Warabi M, Kitamura M. Prognostic value of concomitant resection of extra-hepatic disease in patients with liver metastases of colorectal origin. Surg. 2008;143:706-14.

17. Adam R, Frilling A, Elias D, Laurent C, Ramos E, Capussotti L, et al. Liver resection of colorectal metastases in elderly patients. Br J Surg. 2010;97:366-76.

18. Gasser E, Braunwarth E, Riedmann M, Cardini B, Fadinger N, Presl J, et al Primary tumour location affects survival after resection of colorectal liver metastases: A two-institutional cohort study with international validation, systematic meta-analysis and a clinical risk score. Batra SK, editor. PLoS One. 2019;14:e0217411. 
19. Leung U, Gönen M, Allen PJ, Kingham TP, DeMatteo RP, Jarnagin WR, et al. Colorectal Cancer Liver Metastases and Concurrent Extrahepatic Disease Treated with Resection. Ann Surg. 2017;265:15865.

20. Hasselgren K, Isaksson B, Ardnor B, Lindell G, Rizell M, Strömberg C, et al. Liver resection is beneficial for patients with colorectal liver metastases and extra-hepatic disease. Ann Transl Med. 2020;8:1099.

21. Hadden WJ, de Reuver PR, Brown K, Mittal A, Samra JS, Hugh TJ. Resection of colorectal liver metastases and extra-hepatic disease: a systematic review and proportional meta-analysis of survival outcomes. HPB (Oxford). 2016;18:209-20.

22. Elias D, Liberale G, Vernerey D, Pocard M, Ducreux M, Boige V, et al. Hepatic and Extra-hepatic Colorectal Metastases: When Resectable, Their Localization Does Not Matter, But Their Total Number Has a Prognostic Effect. Ann Surg Oncol. 2005;12:900-9.

23. Hwang M, Jayakrishnan TT, Green DE, George B, Thomas JP, Groeschl RT, et al. Systematic review of outcomes of patients undergoing resection for colorectal liver metastases in the setting of extra hepatic disease. Eur J Cancer. 2014;50:1747-57.

24. Pulitanò $C$, Bodingbauer M, Aldrighetti L, de Jong MC, Castillo F, Schulick RD, et al. Liver resection for colorectal metastases in presence of extra-hepatic disease: results from an international multiinstitutional analysis. Ann Surg Oncol. 2011;18:1380-8.

25. Chua TC, Yan TD, Zhao J, Morris DL. Peritoneal carcinomatosis and liver metastases from colorectal cancer treated with cytoreductive surgery perioperative intraperitoneal chemotherapy and liver resection. Eur J Surg Oncol. 2009;35:1299-305.

26. 26.

27. Carpizo DR, Are C, Jarnagin W, Dematteo R, Fong Y, Gönen M, et al. Liver resection for metastatic colorectal cancer in patients with concurrent extra-hepatic disease: results in 127 patients treated at a single center. Ann Surg Oncol. 2009;16:2138-46.

28. Imai K, Castro Benitez C, Allard M-A, Vibert E, Sa Cunha A, Cherqui D, et al. Potential of a cure in patients with colorectal liver metastases and concomitant extra-hepatic disease. J Surg Oncol. 2017;115:488-96.

29. Brouquet A, Abdalla EK, Kopetz S, Garrett CR, Overman MJ, Eng C, et al. High survival rate after twostage resection of advanced colorectal liver metastases: response-based selection and complete resection define outcome. J Clin Oncol. 2011;29:1083-90.

30. Mise Y, Kopetz S, Mehran RJ, Aloia TA, Conrad C, Brudvik KW, et al. Is complete liver resection without resection of synchronous lung metastases justified? Ann Surg Oncol. 2015;22:1585-92.

\section{Figures}




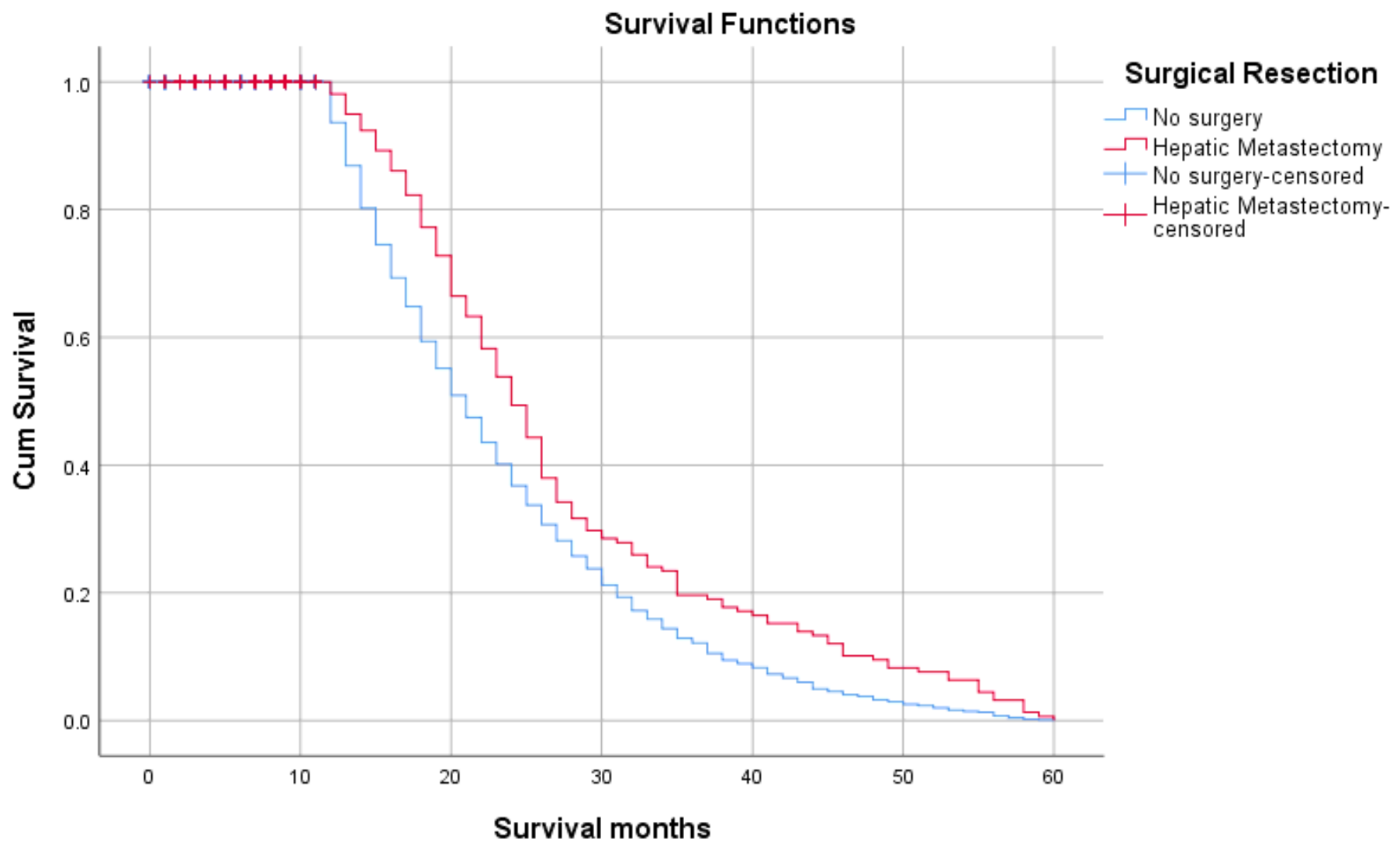

Figure 1

Kaplan-Meier curve of the survival function of CRLM patients who either underwent Hepatic Metastectomy or not. Log-rank test: $\chi 2(1)=18.58, p<0.0001$. 